\title{
NEUROPEPTIDES
}

\section{Central Ventilatory Effects of Thyrotropin-Releasing Hormone in the Conscious Rat}

\author{
S. VONHOF, A.-L. SIRÉN, and G. Z. FEUERSTEIN* \\ Department of Neurology, Uniformed Services University of the Health Sciences, 4301 Jones Bridge \\ Road, Bethesda, MD $20889-4799$ USA, *Smith Kline \& Beecham, Research and Development, 709 \\ Swedeland Road., King of Prussia, PA 19406, USA. (Reprint requests to SV)
}

\begin{abstract}
Thyrotropin-releasing hormone was shown to exert potent ventilatory effects after central administration. These data, however, were derived from studies using anesthetized animal preparations. Since TRH elicits strong arousal reactions, the observed ventilatory effects of TRH under anesthesia may have been due to nonspecific reduction in the anesthetic state of the animals. In order to clarify the extent to which the reversal of anesthesia may change ventilatory parameters after TRH application, we investigated the effect of TRH on ventilation rate, relative tidal volume, relative respiratory minute volume, $\mathrm{CO}_{2}$ production $\mathrm{CO}_{2}$ consumption, and locomotor activity in the conscious, unrestrained rat.

Intracerebroventricular application of TRH induced a dose-dependent, sustained increase in ventilation rate, relative tidal volume, and relative respiratory minute volume of maximally $128 \%, 890 \%$, and $235 \%$, respectively. In addition, $\mathrm{CO}_{2}$ production and $\mathrm{O}_{2}$ consumption were elevated by 4.6 and 11.7 fold, while no significant changes in locomotor activity were observed. The results suggest that TRH stimulates ventilation by a mechanism independent of its analeptic properties.
\end{abstract}

\section{Introduction}

The tripeptide Glp-His-Pro- $\mathrm{NH}_{2}$, thyrotropin-releasing hormone (TRH), was the first hypothalamic, hypophysiotropic releasing factor to be characterized, marking the initial development of the field of neuroendocrinology (1). More recent evidence, however, revealed that immunoreactive TRH is not only confined to hypothalamic nuclei

Date received 12 January 1990

Date accepted 27 August 1990 involved in the regulation of hypophyseal thyrotropin release, but is widely distributed throughout the central nervous system (CNS), including telencephalic and medullary structures $(2,3)$. Moreover, high affinity TRH receptors have been localized in various CNS sites (4) suggesting that TRH may participate in the mediation or modulation of a variety of CNS functions under physiological conditions. This hypothesis is further validated by the profound effects of TRH on behavioral and autonomic functions after central and peripheral administration in experimental 
animals $(5,6,7)$. In addition to its potent cardiovascular effects, including increases in arterial pressure and heart rate (5), TRH has been shown to increase ventilation in the anesthestized rat after intracerebroventricular (icv) application (6) or after microinjection into various brainstem structures (8). Moreover TRH was shown to induce rhythmic depolarisations of neurons in the respiratory division of the nucleus tractus solitarii (9). TRH may therefore play a significant role in the central regulation of ventilation. In most of these studies, however, the animals were anesthetized with urethane $(10,11)$, halothane $(6)$, or urethane-chloralose (12). Since the central application of TRH potently reverses the effects of various centrally acting drugs, including several anesthetics such as barbiturates and ethanol (13, 14 ), the arousal reaction produced by TRH application (15) may reduce the anesthetic state of the animal leading to an increased respiratory reaction to surgical stress or fixation in a stereotaxic apparatus. In order to determine whether the effects of TRH on respiratory parameters observed in anesthetized rats were due to a specific stimulation of central ventilatory control mechanisms or rather to a general arousal reaction leading to a reversal of the anesthetic state, we investigated ventilatory responses and $L A$ after icv injections of TRH in the conscious unrestrained rat.

\section{Materials and Methods}

Male Sprague Dawley rats (375-395g) were obtained from Taconic Farms (Germantown, NY) and housed at controlled temperature $\left(22^{\circ} \mathrm{C}\right)$ and $12 \mathrm{~h}$ light cycle with free access to food and water. Stainless steel guide cannulas were implanted prior to the experiment (coordinates: $-0.8 \mathrm{~mm}$ ap, $-1.2 \mathrm{~mm}$ lat from bregma) under halothane anesthesia ( $2 \%$ in oxygen). The animals were allowed to recover for at least $12 \mathrm{~h}$. All experiments were conducted between 8 a.m. and 6 p.m.

Ventilatory parameters were quantified by means of the OXYMAX '85 system (Columbus Instr., Ohio) for measurements of ventilation rate (f), relative tidal volume $\left(\mathrm{rV}_{\mathrm{T}}\right), \mathrm{O}_{2}$ consumption, and $\mathrm{CO}_{2}$ production. The animals were placed in transparent plexiglass chambers of 6.551 volume with a constant flow of 21 of room air per min. Measurements were performed every $2 \mathrm{~min}$.
Ventilation rate $(f)$ and $\mathrm{rV}_{\mathrm{T}}$ were determined based on the frequency (respirations/min) and amplitude (arbitrary units) of pressure changes due to the ventilatory movements of the animal's thorax. The relative ventilatory minute volume $\left(\mathrm{r} \dot{\mathrm{V}}_{\mathrm{E}}\right)$ was then calculated as the arithmetical product of $f$ and $\mathrm{rV}_{\mathrm{T}}$. The $\mathrm{O}_{2}$ and $\mathrm{CO}_{2}$ contents of the animal chambers were measured against a reference chamber with an equal room air flow of 2 $1 /$ min. Arithmetical differences between the reference and animal chambers were expressed as $\mathrm{O}_{2}$ consumption and $\mathrm{CO}_{2}$ production respectively.

One hour after the start of the experiment the animals $(n=5)$ received a control injection of artifical cerebrospinal fluid (CSF) and consecutive injections of $0.25,1.25,2.5,25$ and $50 \mathrm{nmol}$ of TRH (Bachem) in $10 \mu$ l of artificial CSF icv. Injections were performed manually over $10-15 \mathrm{~s}$, using a 30 gauge needle ( $7.5 \mathrm{~mm}$ length) connected to a $25 \mu \mathrm{l}$ Hamilton syringe by PE-50 tubing. In parallel with the measurements of ventilatory mechanics and gases, the locomotor activity (LA) of the animals was monitored, using the OptoVarimex system (Columbus Instr., Ohio). The estimation of locomotor activity is based on the interruption of infrared light beams caused by movements of the animal. The observation period after each injection lasted $1 \mathrm{~h}$. After the experiment, the animals were sacrificed and the location of the icv injection was verified by dye application. Baseline conditions were determined after the injection of artifical CSF as means over the last $10-20 \mathrm{~min}$ of the respective observation period. Changes $(\Delta)$ of $f, r V_{T}, r \dot{V}_{E}, O_{2}$ consumption, and $\mathrm{CO}_{2}$ production were calculated using a spreadsheet program (Framework, Microsoft). Dose related effects were assessed by the calculation of approximate curve areas of the parameter chnges over the $1 \mathrm{~h}$ observation periods, using a trapezoidal method.

Statistical evaluation was done according to Kruskal-Wallis followed by Mann-Whitney-U test (16). Unless otherwise stated, the results are expressed as means \pm standard error of the mean (S.E.M.) for the indicated number of animals.

\section{Results}

TRH icv caused a dose dependent sustained increase of $f$ (curve areas) to a maximum of $128 \%$ 


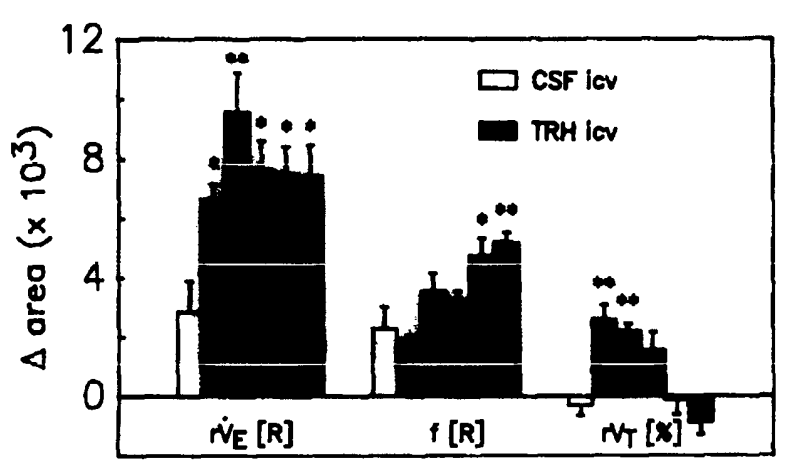

Fig. 1 Effects of TRH on relative ventilatory minute volume $\left(r \dot{V}_{E}\right.$, [respirations $\left.(R)\right]$, ventilatory rate $(f,[R])$, and relative tidal volume $\left(\mathrm{rV}_{\mathrm{T}},[\%]\right)$ after consecutive icv administration of $0.25,1.25,2.5,25$ and 50 nmoles in $10 \mu l$ artificial CSF. Data are expressed as approximate curve areas of parameter changes over $1 \mathrm{~h}$ after each injection. ${ }^{*}(p<0.05)$ and ** $(p<0.01)$ denote statistical significance, when compared to vehicle (artificial CSF) injection (Kruskal-Wallis, $n=5$ ).

compared to vehicle control after the highest dose of $50 \mathrm{nmol}$ icv ( $\mathrm{p}<0.01, \mathrm{n}=5$; Fig. 1). $\mathrm{RV}_{\mathrm{T}}$ was maximally stimulated ( 8.9 fold) after the lowest dose of TRH $(0.25 \mathrm{nmol} ; \mathrm{p}<0.01)$. Increasing doses, however, reduced $\mathrm{rV}_{\mathrm{T}}$ to levels comparable to those seen after artifical CSF icv (Fig. 1). Nevertheless, $r \dot{V}_{E}$ was increased to a maximum of $235 \%$ compared to vehicle alone after $1.25 \mathrm{nmol}$ TRH icv ( $p<0.01)$, but seemed to decrease somewhat after injection of higher doses (Fig. 1). The maximum effects of TRH on $\mathrm{CO}_{2}$ production and $\mathrm{O}_{2}$ consumption were achieved after the $1.25 \mathrm{nmol}$ dose with sustained increases of 4.6 and 11.7 respectively compared to control injections ( $p$ $<0.01$; Fig. 2). Larger doses of TRH, however, decreased $\mathrm{CO}_{2}$, production to a higher degree than $\mathrm{O}_{2}$ consumption.

Locomotor activity (LA) after artifical CSF icv was $520 \pm 172$ counts $/ \mathrm{h}$, and increased to $717 \pm 274$ $(0.25 \mathrm{nmol}), 1620 \pm 229(1.25 \mathrm{nmol}), 1420 \pm 448$ $(2.5 \mathrm{nmol}), 1343 \pm 248(25 \mathrm{nmol})$ and $1101 \pm 391$ counts/h $(50 \mathrm{nmol})$ after icv injections of TRH. Although there appeared to be a dose-related increase of LA, especially after the injection of $1.25 \mathrm{nmol}$ TRH icv, no statistical significance was found when the TRH treatment was compared to vehicle injections using the Kruskal-Wallis test. Application of the Mann-Whitney- $U$ test alone, however, yielded $\mathrm{p}$ values of $0.027(1.25 \mathrm{nmol})$ and
$0.044(25 \mathrm{nmol})$ when the treatment groups were compared to control injections. Since there exists an increased possibility of finding significant results when several tests are performed simultaneously, the adjustment of the statistical $\alpha$-level according to the Bonferroni procedure (17) or others is strongly advised (18). Since the calculated $p$ values of both dosage groups do not reach or fall below the adjust $\alpha$-value $\left(\alpha^{*}=0.01\right)$, both measurements have to be considered nonsignificant at $\alpha=0.05$. In order to resolve this controversy, another set of animals was prepared as described above. Instead of consecutive, increasing doses of TRH, only one dose (1.25nmol, $n=6$ ) was injected icv $1 \mathrm{~h}$ after the onset of the experiment. The resulting changes in ventilator and locomotor activities were compared to singie icv injections of $10 \mu l$ artificial CSF $(n=5)$, which were performed in a similar manner. The t-test for independent samples was used for statistical evaluation. Relative respiratory minute volume $\left(\mathrm{r} \dot{\mathrm{V}}_{\mathrm{E}}\right.$ was increased by $157 \%(\mathrm{p}<0.05)$ after $1.25 \mathrm{nmol}$ TRH icv, while $\mathrm{f}$ (curve areas: 2510 \pm 183 vs. $1547 \pm 460$ respirations $/ h$ after CSF icv), $r V_{T}$, and LA activity were not statistically different from CSF injections (Fig. 3).

\section{Discussion}

The present study demonstrates the effects of TRH on respiratory mechanics, gas exchange and

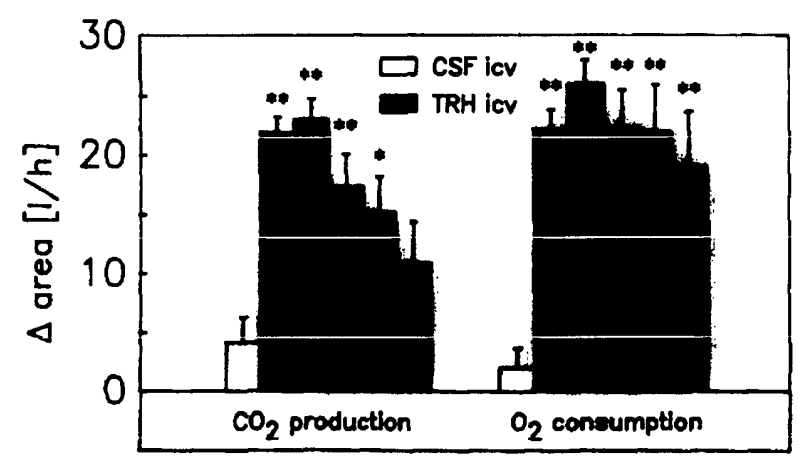

Fig. 2 Effects of TRH on $\mathrm{CO}_{2}$ production and $\mathrm{O}_{2}$ consumption [l/h] after consectuvie icv administration of increasing doses. Data are expressed as approximate curve areas of parameter changes over $1 \mathrm{~h}$ after each injection. ${ }^{*}(p<0.05)$ and ${ }^{* *}(p<0.01)$ denote statistical significance, when compared to vehicle (artificial CSF) injection (Kruskal-Wallis, $\mathbf{n}=$ 5). 


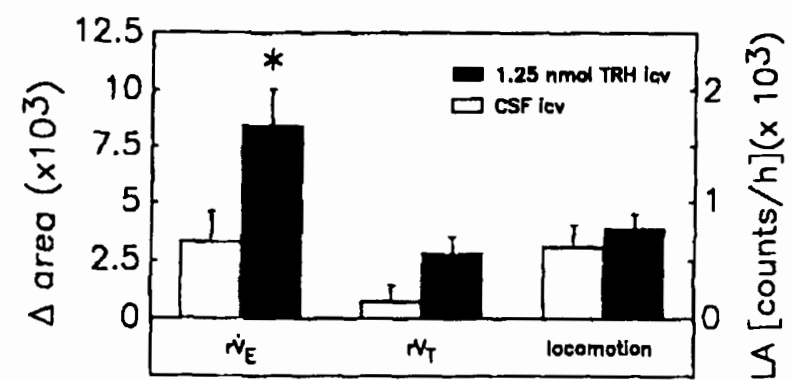

Fig. 3 Effect of a single dose of TRH $(1.25 \mathrm{nmol} ; n=6)$ or $10 \mu$ artifical CSF $(n=5)$ icv on $r \dot{V}_{E}[R], r V_{T}[\%]$ (left ordinate), and locomotor activity (LA, [counts/h], right ordinate). Data for $r V_{E}$ and $r V_{T}$ are expressed as approximate curve areas of parameter changes over $1 \mathrm{~h}$ following the injection of $1.25 \mathrm{nmol}$ TRH or $10 \mu \mathrm{l}$ CSF, whereas LA is derived by simple summation of LA counts over the identical time period.

* ( $p<0.05, t$-test) denotes statistical significance, when compared to CSF injections.

locomotion after icv application in the conscious unrestrained rat. The results indicate that TRH in pico- to nanomole doses stimulates $r \dot{V}_{\mathrm{E}}$ due to an increase of both, $f$ and $\mathrm{rV}_{\mathrm{T}}$. While low doses of TRH appear to exclusively stimulate $r V_{T}$, higher doses lead to a decrease of $\mathrm{rV}_{\mathrm{T}}$, combined with an enhanced $\mathrm{f}$. Therefore the stimulatory action of TRH on $r \dot{V}_{E}$ may be divided into a low dose component ( 0.25 to 1.25 nmoles icv.), driven primarily by an activation of $\mathrm{V}_{\mathrm{T}}$, and a high dose element ( 2.5 to 50.0 nmoles icv.), in which the respiratory simulation is primarily due to an increased $\mathrm{f}$. Simultaneous with stimulation of respiratory mechanics, $\mathrm{CO}_{2}$ production and $\mathrm{O}_{2}$ consumption were drastically increased after low doses of TRH icv with no further increment after higher doses. In fact, the increases of $\mathrm{CO}_{2}$ production and $\mathrm{O}_{2}$ consumption after higher doses $(>2.5$ nmol icv) were less than the corresponding changes induced by the $1.25 \mathrm{nmol}$ dose, indicating a possible development of tachyphylaxis to this TRH effect. Moreover, TRH was unable to induce significant changes of LA within the tested range of TRH doses, suggesting the involvement of different mechanisms in the locomotor and ventilatory responses to TRH.

Stimulatory effects of centrally administered TRH on cardiorespiratory functions have been reported in various species $(6,10,11,12)$. In the anesthetized rat, TRH was shown to increase $f$ after icv injection of pico- to nanomolar doses $(6$, 10). This stimulatory effect on $f$ was combined with a decrease of $\mathrm{V}_{\mathrm{T}}$ leading to an either unchanged (10) or increased (6) $\dot{\mathrm{V}}_{\mathrm{E}}$. The underlying mode of action may involve an activation of inspiratory off-switch mechanisms in the brainstem, possibly due to an increased sensitivity to vagal afferent inputs (20).

The results of the present study suggest that TRH stimulates ventilation unrelated to the state of consciousness of the animal. Moreover, a striking difference to previous studies using anesthetized animal preparations $(6,10)$ is the dose-related stimulation of $V_{T}$, which appears to be primarily responsible for the elevation of $\dot{V}_{E}$ over the low dose range. Interestingly, injection of a single dose $(1.25 \mathrm{nmol})$ of TRH per rat produced a somewhat reduced effect on all measured parameters compared to the effects of the same dose administered after previous injections of CSF and $0.25 \mathrm{nmol}$ TRH. The mechanism underlying this phenomenon is unclear. Repeated icv injections of saline at hourly intervals appear to exert significantly decreasing responses of $f$, while no changes of $V_{\mathrm{T}}$ or $r \dot{V}_{\mathrm{E}}$ could be detected (unpublished observation). This may reflect a behavioral habituation to stress imposed by the handling of the animals during the injection itself. Since TRH was shown to enhance the reaction to stress paradigms, such as acoustic startle (19), previous administration of TRH may enhance the ventilatory responses to subsequent injections up to a degree where tachyphylaxis, presumably due to TRH receptor down-regulation exerts a counteracting effect.

The discrete mechanisms involved in the effects of TRH on respiratory mechanics and gases are still unknown. They likely involve specific TRH receptors on brainstem nuclei participating in the central control of respiration, such as the dorsal motor nucleus of vagus and the nucleus tractus solitarii (4). This hypothesis is corroborated by studies showing that depletion of brain TRH content using the serotoninergic neurotoxin 5 , 7-dihydroxytryptamine, results in an upregulation of TRH receptors in brainstem and pons $(21,22)$ and an enhanced sensitivity to the respiratory stimulation by TRH (23). 
The present results further indicate that TRH icv potently stimulates $\mathrm{CO}_{2}$ production and $\mathrm{O}_{2}$ consumption. The increase of $\mathrm{CO}_{2}$ production may be accompanied by a decrease of $\mathrm{P}_{\mathrm{a}} \mathrm{CO}_{2}$ leading to an increase of arterial $\mathrm{pH}$ as reported by Hedner et al. (6). However, no significant changes of $\mathrm{P}_{\mathrm{a}} \mathrm{O}_{2}$ could be observed in this study. Additionally, TRH was shown to increase peripheral metabolism by direct and indirect means. Griffiths et al. (24) reported an activation of the metabolic rate of brown adipose tissue of rats which was presumably mediated by a stimulation of sympathetic nerve activity (5). Moreover, the stimulation of LA by TRH as previously shown by Andrews and Sahgal (7) may constitute an indirect mode of metabolic activation due to an increased peripheral energy consumption. It, therefore, appears likely that the increases of $\mathrm{CO}_{2}$ production and $\mathrm{O}_{2}$ consumption observed in the present study reflect a ventilatory compensation of enhanced peripheral metabolic demands.

Although a reflex activation of central respiratory control mechanisms through a locomotiondependent increase of $\mathrm{p}_{\mathrm{a}} \mathrm{CO}_{2}$ leading to a stimulation of $\dot{\mathrm{V}}_{\mathrm{E}}$ may be possible, the mediation of the ventilatory effects of TRH by central TRH receptors appears to be the pivotal mechanism of action as shown by the correlation of ventilatory responses of TRH with TRH receptor densities in CNS structures (23). Moreover, in anesthetized animals, TRH icv produces a stimulation of ventilation accompanied by a decrease of $\mathrm{p}_{\mathrm{a}} \mathrm{CO}_{2}$, emphasizing the central mode of action (6). It is yet unclear, however, to what extent peripheral metabolic demands influence the respiratory patterns elicited by TRH. The present study revealed a dissociation of ventilatory and LA effects of TRH icv (Fig. 3). Thus, a single dose of TRH injected icv, clearly stimulated respiration as seen by an increase of $r V_{E}$, while virtually no change of LA occurred. Moreover, the lowest dose of TRH used in this study $(0.25 \mathrm{nmol})$ was able to maximally stimulate $\mathrm{V}_{\mathrm{T}}, \mathrm{CO}_{2}$ production, and $\mathrm{O}_{2}$ consumption (Figs $1 \& 2$ ), while mean locomotor activity was increased by only $38 \%$ compared to icv injections of artifical CSF. Therefore, it appears unlikely that the ventilatory effects of TRH may primarily constitute a reflectory activation due to changes in metabolic homeostasis following an increased LA. Higher doses of TRH (10 to $100 \mu \mathrm{g}$ administered in single injections in $2 \mu$ l volumes), however, were shown to significantly increase LA, possibly dependent on a diurnal susceptibility rhythm (7). Therefore with administration of higher TRH doses, LA may become a significant factor in the stimulation of respiration via an increased muscular metabolism.

In summary, the results of the present study indicate that TRH after icv administration in conscious rats stimulates ventilation and peripheral metabolism as evidenced by an increase of $\mathrm{CO}_{2}$ production and $\mathrm{O}_{2}$ consumption. The stimulatory effect of TRH appears to result from an activation of mechanisms involved in the central control of ventilation. Furthermore, the anesthesia-reversing properties of TRH may be of negligible importance in eliciting the ventilatory effects of TRH in studies using anesthetized animals.

\section{Acknowledgements}

The opinions or assertions contained herein are the private ones of the authors and are not to be construed as official or as necessarily reflecting the views of the Department of Defence or the Uniformed Services University of the Health Sciences. The experiments reported herein were conducted according to the principles set forth in the 'Guide for Care and Use of Laboratory Animals', Institute of Laboratory Animal Resources, National Research Council (DHEW Publication No. NIH 85-23, 1985) and were supported in part by Uniformed Services University of the Health Sciences protocol RO9232.

\section{References}

1. Böler, J., Enzmann, F., Folkders, K., Bowers, C. Y. and Schally, A. V. (1969). The identity of chemical and hormonal properties of the thyrotropin-releasing hormone and pyroglutamyl-histidyl-proline amide. Biochemical and Biophysical Research Communications 37: 705-710.

2. Brownstein, M. J., Palkovits, M., Saavedra, J. M., Bassiri, R. M. and Utiger, R. D. (1974). Thyrotropin-releasing hormone in specific nuclei of rat brain. Science 185: 267-269.

3. Yamazoe, M., Shiosaka, S., Shibasaki, T., Ling, N., Tateishi, K., Hashimura, E., Hamaoka, T., Kimmel, J. R., Matsuo, H. and Tohyama, M. (1984). Distribution of six neuropeptides in the nucleus tractus solitarii of the rat: An immunohistochemical analysis. Neuroscience 13: 1243. 1266. 
4. Sharif, N. A. (1989). Quantitative autoradiography of TRH receptors in discrete brain regions of different mammalian species. In: Metcalf, G. and Jackson, I. M. D. (eds) Annals of the New York Academy of Sciences, Vol. 553: Thyrotropin-releasing hormone: Biomedical significance, New York Academy of Sciences, New York, p. 147-175.

5. Sirén, A.-L., Lake, C. R. and Feuerstein, G. (1988). Hemodynamic and neural mechanisms of action of thyrotropin-releasing hormone in the rat. Circulation Research 62: 139-154.

6. Hedner, J., Hedner, T., Wessberg, P., Lundberg, D. and Jonason, J. (1983). Effects of TRH and TRH analogues on the central regulation of breathing in the rat. Acta Physiologica Scandinavica 117: 427-437.

7. Andrews, J. S. and Sahgal, A. (1983). The effects of thyrotropin-releasing hormone, metabolites and analogues on locomotor activity in rats. Regulatory Peptides 7: 97-109.

8. McCown, T. J., Hedner, J. A., Towle, A. C., Breese, G. R. and Muelier, R. A. (1986). Brainstem localization of a thyrotropin-releasing hormone-induced change in respiratory function. Brain Research 373: 189-196.

9. Dekin, M. S., Richerson, G. B. and Getting, P. A. (1985). Thyrotropin-releasing hormone induces rhythmic bursting in neurons of the nucleus tractus solitarius. Science 229: 67-69.

10. Koivusalo, F., Paakkari, I., Leppäluoto, J. and Karppanen, H. (1979). The effect of centrally administered TRH on blood pressure, heart rate and ventilation in rat. Acta Physiologica Scandinavica 106: 83-86.

11. Yamamoto, Y., Lagercrantz, H. and von Euler, C. (1981). Effects of substance $P$ and TRH on ventilation and pattern of breathing in newborn rabbits. Acta Physiologica Scandinavica 113: 541-543.

12. Homma, I., Oouchi, M. and Ichikawa, S. (1984). Facilitation of inspiration by intra-cerebroventricular injection of thyrotropin-releasing hormone in rabbits. Neuroscience Letters 44: 265-269.

13. Breese, G. R., Cott, J. M., Cooper, B. R., Prange Jr., A. J. and Lipton, M. A. (1974). Antagonism of ethanol narcosis by thyrotropin-releasing hormone. Life Sciences 14: 1053-1063

14. Breese, G. R., Cott, J. M., Cooper, B. R., Prange jr., A. J., Lipton, M. A. and Plotnikoff, N. P. (1975). Effects of thyrotropin-releasing hormone (TRH) on the actions of pentobarbital and other centrally acting drugs. Journal of Pharmacology and Experimental Therapeutics 193: 11-22.

15. Sharp, T., Tulloch, I. F., Bennett, G. W., Marsden, C. A., Metcalf, G. and Dettmar, P. W. (1984). Analeptic effects of centrally injected TRH and analogues of TRH in the pentobarbitone-anesthetized rat. Neuropharmacology 23: 339-348.

16. Theodorsson-Norheim, E. (1986). Kruskal-Wallis test: Basic computer program to perform nonparametric oneway analysis of variance and multiple comparisons on ranks of several independent samples. Computer Methods and Programs in Biomedicine 23: 57-62.

17. Holm, S. (1979). A simple sequentially rejective multiple test procedure. Scandinavian Journal of Statistics 6: 65-70.

18. Krauth, J. (1988). Distribution-free statistics. Elsevier, Amsterdam.

19. Sananes, C. B., Melia, K. R. and Davis, M. (1989) Local infusion of TRH or CGRP in the central nucleus of the amygdala enhances acoustic startle. Society for Neuroscience, Abstracts 15/1: 712, 288.9.

20. Hedner, J. (1983). Neuropharmacological aspects of central respiratory regulation. Acta Physiologica Scandinavica, Suppl. 524: 1-109.

21. Sharif, N. A., Towle, A. C., Burt, D. R., Mueller, R. A. and Breese, G. R. (1989). Cotransmitters: Differential effects of serotonin (5-HT)-depleting drugs on levels of 5-HT and TRH and their receptors in rat brain and spinal cord. Brain Research 480: 365-371.

22. Ogawa, N., Kabuto, H., Hirose, Y., Nukina, I. and Mori, A. (1985). Up-regulation of thyrotropin-releasing hormone (TRH) receptors in rat spinal cord after codepletion of serotonin and TRH. Regulatory Peptides 10: 85-90.

23. Mueller, R. A., Towle, R. A. and Breese, G. R. (1984). Supersensitivity to the respiratory stimulatory effect of TRH in 5,7-dihydroxytryptamine-treated rats. Brain Research 298: 370-373.

24. Griffiths, E. C., Rothwell, N. J. and Stock, M. J. (1989). Thermogenic effects of TRH and its analogues in the rat. In: Metcalf, G. and Jackson, I. M. D. (eds) Annals of the New York Academy of Sciences, Vol. 553: Thyrotropinreleasing hormone: Biomedical significance, New York Academy of Sciences, New York, p. 569-570. 